\title{
How to produce an annual report
}

\author{
Adrian James and Martin Donovan
}

\begin{abstract}
In the new style NHS an annual report is essential for all services. Senior registrars have the necessary skills and are ideally placed to co-ordinate such an enterprise as part of their management training. The typical structure for such a report is described and suggestions are made on content and format. Piffalls are outlined from the authors' experience.
\end{abstract}

Data collection and information exchange is a rapidly expanding component of health services. An annual report is crucial in this respect and provides an important opportunity to publicise and contract for services. Senior registrars are well placed to co-ordinate such an enterprise, which is useful management experience and helps to increase their knowledge of service provision.

This article describes the production of an annual report for the Forensic Psychiatry Services at Langdon Hospital (part of the Exeter and District Community Health Service Trust). The senior registrar in the service was asked to edit the report which resulted in a 90 page document. The basic structure described can be modified to meet the requirements of individual services.

\section{Who is it for?}

It is important to discover who will receive and read the report. The style and content are matched to the readership and will vary between services. The readership will range from knowledgeable professionals such as clinicians and managers to lay persons on trust boards and within purchasing authorities. The report is inevitably a compromise to meet the needs of disparate groups. Most people who receive a copy will give it a cursory glance, so items of specific interest must be easily accessible. A small number of people will read the report in detail, so every page must be prepared with diligence and care.

\section{Preparation}

The report should be a multidisciplinary effort and used to promote cohesion between fellow professionals. An initial meeting should agree a format and a primary theme for that year such as audit, quality or the place of information technol-
Table 1. Annual Report

List of Contents

Foreword

History of the service

Current service provision

Support services

Information technology

Operational statistics

Quality and audit

Education and professional development

Research

Contemporary issues

Future developments

Acknowledgements

Appendices

ogy in service development. Submissions should be prepared by departmental heads and the contributions edited and combined to reflect the unified team approach. An example of a list of contents is found in Table 1.

\section{Format}

A brief historical perspective and overview of clinical provision will be appreciated by readers who are unfamiliar with the service.

Care should be taken not to make extravagant or unsubstantiated claims and it is prudent to take a conservative view about future aims and objectives - failure to achieve these will need to be addressed in the next report.

Financial aspects are best left to accountants and will not normally form part of a service orientated annual report. These will be included in the trust or directly managed unit report compiled by senior management. With the increasing move towards clinical directorates and individual budgets, this situation may change.

\section{Operational statistics}

An important part of the annual report is the collection and presentation of basic patient data. This information will be available from data collection systems within the service. What 
information is held and who has it should be identified at an early stage. Very often information is discovered too late or the information required is simply not available in a readily accessible form. The help of a computer enthusiast, or information technology officer, is essential. Basic data are presented on referrals, admissions, out-patients and discharges corresponding to financial years. Demographic, legal, physical and mental health, and other relevant data should be presented and interpreted along with information regarding the referral process. Increasingly purchasers need to know the share of the service being used by their customers. Information will need to be presented to reflect these points. Tables, graphs and bar charts can be used in the form of appendices to the report. A commentary is essential to interpret the data and establish the theme of the report.

\section{Presentation}

A professional format will impress the readers. The most up to date word processing package should be used along with the neatest type face. The spacing of the report is important with a need to compromise between clear layout and wastefulness. Single side typing is recommended with one and a half spaces between lines. All pages should be numbered with a clear list of contents situated at the beginning of the report. The report should be bound adequately so that the pages do not come adrift. The trust or directly managed unit logo should appear on the cover.

\section{Acknowledgements}

Individuals who have contributed to the report must be fully acknowledged.

\section{Appendices}

Much of the routine information can be presented in appendices so that readers can be selective. Appendices could include publications, courses available at the hospital, the personnel establishment, audit programme, quality standards and operational statistics.

All contributors will have their own ideas on style and presentation and so successive drafts should be viewed by a small number of people to avoid confusion. Ultimately a firm editorial stance is needed to avoid delays and to deal with requests for last minute revisions.

When the report is completed a circulation list will need to be drawn up and ownership of the report negotiated. The management board of a trust or directly managed unit may feel that it is their property and responsibility to distribute it. Seek their views before distributing widely, particularly to other services.

\section{Future reports}

The planning of future reports is a priority and this year's report will have uncovered various deficiencies in the way in which data are collected. Attention will need to be given to reviewing database systems and word processing packages, identifying new information to be collected on a prospective rather that retrospective basis and making the report responsive to the users of the service.

\section{Acknowledgements}

We thank the staff at Langdon Hospital for their help in producing the Annual Report for the Forensic Service 1992-93.

*Adrian J. B. James, Senior Registrar in Forensic Psychiatry; and W. M. Donovan, Consultant Forensic Psychiatrist, Langdon Hospital, Exeter Road, Dawlish, Devon EX7 ONR

*Correspondence 